Review

\title{
Macrophage Immunometabolism and Inflammaging: Roles of Mitochondrial Dysfunction, Cellular Senescence, CD38, and NAD
}

\author{
Johnathan R. Yarbro ${ }^{1,2}$, Russell S. Emmons ${ }^{1}$, Brandt D. Pence ${ }^{1,3, *}$ \\ 1 School of Health Studies, University of Memphis, Memphis, TN 38152, USA \\ 2 Bioinformatics Program, University of Memphis, Memphis, TN 38152, USA \\ 3 Center for Nutraceutical and Dietary Supplement Research, University of \\ Memphis, Memphis, TN 38152, USA \\ * Correspondence: Brandt D. Pence, Email: bdpence@memphis.edu; \\ Tel.: +1-901-678-4316.
}

\begin{abstract}
Aging is a complex process that involves dysfunction on multiple levels, all of which seem to converge on inflammation. Macrophages are intimately involved in initiating and resolving inflammation, and their dysregulation with age is a primary contributor to inflammaging - a state of chronic, low-grade inflammation that develops during aging. Among the agerelated changes that occur to macrophages are a heightened state of basal inflammation and diminished or hyperactive inflammatory responses, which seem to be driven by metabolic-dependent epigenetic changes. In this review article we provide a brief overview of mitochondrial functions and age-related changes that occur to macrophages, with an emphasis on how the inflammaging environment, senescence, and NAD decline can affect their metabolism, promote dysregulation, and contribute to inflammaging and age-related pathologies.
\end{abstract}

KEYWORDS: aging; macrophage; monocyte; NAD; mitochondria; inflammaging; immunometabolism; senescence; SASP; CD38

\section{G Open Access}

Received: 13 April 2020

Accepted: 30 June 2020

Published: 01 July 2020

Copyright (C) 2020 by the author(s). Licensee Hapres, London, United Kingdom. This is an open access article distributed under the terms and conditions of Creative Commons Attribution $\underline{4.0 \text { International License. }}$

\section{ABBREVIATIONS}

$\Delta \Psi \mathrm{m}$, mitochondrial membrane potential; BMDM, bone marrow-derived macrophage; DAMP, damage-associated molecular pattern; ER, endoplasmic reticulum; ETC, electron transport chain; FAO, fatty acid oxidation; HDAC, histone deacetylase; hMDM, human monocyte-derived macrophage; IFN, interferon; IL, interleukin; IMM, inner mitochondrial membrane; KO, knockout; KP, kynurenine pathway; LPS, lipopolysaccharide; mtDNA, mitochondrial DNA; NA, nicotinic acid; NAD, nicotinamide adenine dinucleotide; NAM, nicotinamide; NLR, NOD-like receptor; NMN, nicotinamide mononucleotide; NR, nicotinamide riboside; OMM, outer mitochondrial membrane; OXPHOS, oxidative phosphorylation; PAMP, pathogen-associated molecular pattern; PARP, 
poly-ADP-ribose polymerase; PRR, pattern recognition receptor; RAGE, receptor for advanced glycation end products; RET, reverse electron transport; ROS, reactive oxygen species; SASP, senescence-associated secretory phenotype; SC, senescent cell; SIRT, sirtuin; TCA, citric acid cycle; TFAM, mitochondrial transcription factor A; TNF, tumor necrosis factor; TLR, toll-like receptor

\section{INTRODUCTION}

Aging is the highest risk factor for the majority of chronic diseasesincluding cardiovascular disease, diabetes, stroke, and cancer [1], and a staggering $73 \%$ of all deaths worldwide in 2017 were attributable to chronic diseases [2]. Underlying most age-related pathologies is a sterile, chronic, systemic inflammatory state (inflammaging), which is likely a result of a host of factors that become dysregulated with age [3,4]. These "hallmarks of aging" include mitochondrial dysfunction, altered metabolic signaling, defective autophagy and mitophagy, dysbiosis, diminished proteostasis, stem cell exhaustion, telomere attrition, epigenetic changes, genomic instability, and cellular and immune senescence [1,3,5]. These hallmarks are interconnected and co-occur with one another, but all converge on inflammation, as an impairment in any of these can promote inflammation and affect the other hallmarks [5]. The causal driver of inflammaging appears to be an accumulation of damage over time, alongside the gradual decrease in the body's ability to repair from damage and maintain homeostasis [5,6]. Damaged cells, cell debris, and misfolded/misplaced molecules (garbage) can be sensed by pattern recognition receptors (PRRs) of the innate immune system as damageassociated molecular patterns (DAMPs) and promote inflammation. Inflammaging and dysbiosis drive intestinal permeability resulting in increased circulating levels of bacterial products which further stimulate PRRs via their pathogen-associated molecular patterns (PAMPs) [7]. Chronic stimulation of PRRs and cytokine receptors by DAMPs, PAMPs, and inflammatory cytokines plays a major role in the development of inflammaging, and macrophages are central in this phenomenon [6]. Macrophages play a critical role in removing garbage and bacteria, maintaining homeostasis, and regulating inflammation, and undergo various changes with age which can contribute to age-related pathologies, largely by increasing inflammation. Several studies have demonstrated that macrophages can actively drive age-related pathologies, as depleting macrophages led to diminished inflammatory responses and improved survival outcomes [8-11].

\section{MACROPHAGE POLARIZATION}

Macrophages exhibit exceptional plasticity and can adjust their phenotype in response to various signals in their environment. Traditionally, they have been classified as resting (M0), classically activated (M1), or alternatively activated (M2). Macrophages are generally 
polarized in vitro to a M1 phenotype using lipopolysaccharide (LPS), interferon-gamma (IFN $\gamma$ ), tumor necrosis factor alpha (TNFa) and/or other Toll-like receptor (TLR) ligands [12]. M1 macrophages have primarily been shown to be catabolic, pro-inflammatory, glycolytic, and bactericidal. They secrete a variety of inflammatory/bactericidal mediators including IL-6, TNFa, IL-1 $\beta$, IL-12 and reactive oxygen species (ROS) [12], all of which increase in circulation with age [13,14]. M2 macrophages represent the opposite end of the polarization spectrum from M1 macrophages. They rely mainly on oxidative phosphorylation (OXPHOS) and fatty acid oxidation (FAO) for energy, are generally anti-inflammatory, and are involved in tissue repair, angiogenesis, and phagocytosis [15]. This binary classification of macrophage phenotypes is still commonly used for simplification but is inaccurate as macrophage phenotypes exist in vivo across a wider spectrum [15,16].

The local microenvironment plays a critical role in shaping what genes are expressed [17], and macrophages can display both M1 and M2 markers in vivo and are not necessarily exclusively pro-inflammatory or antiinflammatory [15]. For instance, there is evidence that M2-like macrophages can be pro-inflammatory [18], and that a pro-inflammatory M2 phenotype seems to accumulate in some, but not all, tissues with age [19-24]. M2 phenotypes have recently been divided into M2a, M2b, M2c, and other subdivisions by some authors based off the stimuli used to polarize them in vitro [15]. Traditionally, they have been polarized with IL-4 and IL-13 to the M2a subdivision and most studies generally refer to this subtype when mentioning M2 macrophages. Since macrophages are heterogeneous and the various phenotypes are still being characterized, it is currently unknown exactly how the macrophage phenotypic landscape changes with age, but new metrics from various omics technologies may be able to help elucidate this in the near future [25]. Regardless, it does seem that macrophages increase in number in most, but not all, studied tissue types with age and display an altered physiology that often contribute to pathology [19,22-24,26,27]. Several recent review articles describe these changes in detail [28-30], so we will only briefly mention some of the major changes here which are relevant to this discussion.

\section{AGE-RELATED MACROPHAGE DYSFUNCTION}

Among the age-related changes that occurs to macrophages is a decline in phagocytic ability which has been observed in multiple tissues including the peritoneum [31], lungs [32], bone marrow [33] and brain [34]. This dysfunction could be a consequence of several different factors including senescence [35], defective autophagy [36], reduced NAD availability [37], and impairments in mitochondrial functions such as reduced ATP production, mitochondrial membrane potential $(\Delta \Psi \mathrm{m})$, and increased reactive oxygen species (ROS) production [38,39]. Age-related alterations in macrophage phenotypes may also contribute, as M2-like macrophages are generally more phagocytic and are reduced in some 
tissues. For example, a recent study in Alzheimer's patients reported an increase in $\mathrm{M} 1$ and a decline in the M2b phenotype, which is highly phagocytic [22]. Aging has also been shown to cause an increased number of bone marrow-derived macrophages (BMDMs) that are skewed towards a M1 phenotype and display impaired phagocytosis and cytokine production [24]. Extrinsic factors in the aging microenvironment likely also play a role, as peritoneal macrophages from young mice injected into the peritoneum of aged mice exhibited impaired phagocytic capacity [31]. It is likely that a combination of all these factors, as well as other aging hallmarks, contribute to phagocytic decline.

Many studies have reported altered TLR expression and cytokine production in macrophages as a result of aging. Macrophages from aged individuals generally exhibit increased basal inflammation and exist in a sustained activated state, likely as a result of chronic stimulation by the inflammaging environment [40]. Often accompanying this low-grade basal inflammation is a state of immune paralysis in which effector responses such as phagocytosis, antigen presentation, and wound healing are impaired [40]. There has been a number of contradictory findings reported in the literature with regards to cytokine production following stimulation in aged macrophages, which may be explained by differing study designs, tissue site of origin [41], or other factors. Several studies have shown increased cytokine, ROS, and/or nitric oxide production following stimulation in aged macrophages [8,42-44]. This may be partially due to an epigenetic rewiring process known as trained immunity, in which macrophages and other innate immune cells exhibit enhanced responsiveness to stimuli they have previously encountered [45]. Trained immunity requires a shift in metabolism towards a glycolytic state [46], as it promotes cholesterol synthesis, fumarate accumulation, and glutaminolysis which mediates epigenetic reprogramming [47]. This reprogramming is characterized by trimethylation of lysine 4 at histone 3 (H3K4me3) and acetylation of lysine 27 (H3K27ac) on the promotor region of genes involved in immune signaling and metabolism. This results in increased expression of proinflammatory genes such as IL-6, TNFa, MCP1 , as well as key glycolytic genes such as hexokinase-2 and phosphofructokinase [48].

It has been proposed that lower doses of PAMPs and DAMPs may induce trained immunity, while higher doses can lead to an opposite effect known as immune tolerance [49]. Immune tolerance is characterized by a diminished responsiveness to stimuli, usually as a result of receptor desensitization [45], which has been demonstrated for various TLRs in macrophages [50]. In contrast to the studies mentioned above, several studies have shown that macrophages and monocytes have decreased responsiveness to stimuli [51-55], and these disparate findings could possibly be due to differences in the epigenetic state when analyzed. Immune tolerance and trained immunity have not been well studied in the context of aging, but it is likely that these epigenetic processes play a 
role in inflammaging. Aging involves a complex reshaping of the immune system, and persistent stimulation by DAMPs and PAMPs may drive nonuniform changes which cause some cellular responses to be impaired, some to be preserved, and others to be hyper-activated. As these epigenetic changes are largely dependent on bioenergetic processes, dysfunctional mitochondria and the resulting metabolic derangements may be central to this phenomenon. When PRR stimulation is relatively low, immune cells can efficiently respond by altering their metabolism to maintain adequate production of the necessary biomolecules needed to perform their functions. For instance, upregulating glycolysis to meet the energy demand for effective cytokine and ROS production to kill invading pathogens. Rising PRR stimulation and excessive oxidative stress that occur with aging may induce bioenergetic defects, as the cell cannot keep up with the energy demand, which dysregulates trained immunity and immune tolerance and may contribute to immunosenescence [49]. This has been demonstrated in BMDMs from aged mice which exhibited dysregulated immune tolerance due to an inability to shift from OXPHOS to glycolysis following LPS stimulation [51]. NAD decline with age, which is described in a later section of this review, likely contributes to these defects. NAD-dependent sirtuins play essential roles in regulating metabolic functions and were shown to be involved in initiating and resolving immune tolerance in monocytes via metabolic reprogramming [56,57]. How this precisely contributes to age-related epigenetic changes and macrophage dysfunction has yet to be determined, but it is clear that metabolic dysregulation and mitochondrial impairments play an important role.

\section{MITOCHONDRIA AND AGING}

Mitochondria lie as the central hub for cellular metabolism. Historically, mitochondria have been viewed in the context of ATP generation as the site for the citric acid (TCA) cycle and OXPHOS, however; mounting evidence highlights their role as signaling propagators either through the release of proteins, metabolites, and ROS, or as a scaffold for signaling complexes [58]. Mitochondrial dysfunction contributes to inflammaging and immunosenescence and has been linked to a myriad of diseases including cardiovascular disease, cancer, metabolic diseases, and aging [59-62]. The underlying mechanism by which aging occurs is not fully understood, although many hypotheses have been ventured. Denham Harman put forth the free radical theory of aging in 1956, briefly summarized as the cumulative damage from ROS to DNA, lipids, and proteins which drives aging and age-related diseases [63]. Challenges to this paradigm have arisen with the observations of ROS in normal physiological processes, beneficial hormetic adaptions resulting from low grade exposure to ROS such as with exercise, and observed dysfunction in other organelles including the endoplasmic reticulum (ER) and lysosomes resulting in misfolded proteins [64-66]. Nevertheless, a mounting body of 
evidence have coalesced to highlight a relationship between aging and mitochondrial health.

Inflammatory activation of the immune system can be triggered through sensing by PRR of DAMPs or PAMPs. PRRs constitute a wide range of receptors including NOD-like receptors (NLRs), receptors for advanced glycation end-products (RAGEs), and TLRs that affect inflammatory responses. For instance, mitochondrial DNA (mtDNA), which shares many similarities with bacterial DNA due to their shared prokaryotic origins, can serve as an inflammatory stimulus by acting as a DAMP. The mitochondrial proteome is maintained by mtDNA, distinct from the nuclear genome. mtDNA is vulnerable to mutation and lesion from the hazardous ROS-rich mitochondrial environment as it lacks the protective histone structures of nuclear DNA. Despite this, mtDNA remains functional in the presence of high degrees of mutation load of $60-90 \%$ before defects in OXPHOS manifest [67-69]. However, mtDNA is released from apoptotic and stressed cells $[70,71]$ and is a potent DAMP, activating innate immune cells in a TLR9 [72], NLRP3 inflammasome [73], and cGAS/STING dependent fashion [74]. Indeed, mtDNA has been observed to stimulate immune activation following traumatic injury [72] and heart failure [75]. During aging, mtDNA has been observed to increase in tissues and circulation and correlates with inflammatory markers; further, mtDNA was shown to promote proinflammatory cytokine production in monocytes [76,77]. Understanding of mitochondrial structure and function may shed light on their contribution to inflammaging.

\section{MITOCHONDRIAL STRUCTURE AND FUNCTION}

Mitochondria are dynamic organelles, translocating around the cell and forming interconnected networks. Maintenance, transcription, and packaging of mtDNA is controlled by mitochondrial transcription factor A (TFAM) [78,79]. Mitochondria possess a double membrane, containing an outer mitochondrial membrane (OMM) and invaginated inner mitochondrial membrane (IMM) composed of cardiolipin to form cristae where the OXPHOS machinery is distributed throughout [80]. The electron transport chain (ETC) is composed of a series of 4 protein complexes, CICIV, on the lateral IMM. The final complex, F1F0 ATP synthase is the primary generator of cellular ATP. Briefly, NADH and FADH2 are reduced to $\mathrm{NAD}^{+}$and FAD respectively by a series of redox reactions at complexes I-IV, whereby protons are pumped into the intramembrane space to create the electrochemical gradient $\Delta \Psi \mathrm{m}$ (further reviewed [81]). F1F0 ATP synthase uses the $\Delta \Psi \mathrm{m}$ to catalyze ATP generation from ADP. Besides fueling F1F0 ATP synthase, the $\Delta \Psi \mathrm{m}$ serves as a buffer for $\mathrm{Ca}^{2+}$ and is an effective measure of mitochondrial quality. Maintenance of the $\Delta \Psi \mathrm{m}$ is necessary for driving OXPHOS, maintaining the intramembrane space, and for cellular homeostasis. Interestingly, the $\Delta \Psi \mathrm{m}$ has recently been observed to be heterogenous between cristae throughout mitochondria [80]. The varying $\Delta \Psi \mathrm{m}$ throughout the mitochondria may serve to allow 
for different aspects to focus on various functions such as OXPHOS vs ROS generation. Similarly, it may serve as a protective mechanism to highlight damaged areas or prevent the spread of damage in defective OXPHOS.

At the mitochondrial level, divergent stimuli elicit unique utilization of mitochondria to carry out cellular response. For example, during M1 polarization, nitric oxide induced blunting of oxidative phosphorylation allows for increased ROS production via reverse electron transport (RET) at CI, CIII, and CIV [82]. Additionally, the cessation of electron generation necessitates the use of glycolytically generated ATP to drive F1F0 ATP transport of protons to prevent $\Delta \Psi \mathrm{m}$ depolarization, increasing the $\Delta \Psi \mathrm{m}$ and preventing the release of the pro-apoptosis signal cytochrome $\mathrm{c}$ to the cytosol [83]. Furthermore, mitochondria are recruited to the lysosome to assist in phagosome breakdown with ROS production via the TRAF6-ECSIT complex [84]. Metabolically, succinate accumulates during OXPHOS impairment, resulting in HIF1a stabilization, inflammasome activation, and IL-1 $\beta$ production [85]. Conversely, OXPHOS is necessary for IL-4 mediated polarization. Active flux through OXPHOS promotes cellular aketoglutarate (a-KG), which has been shown to suppress inflammatory gene expression. a-KG impairs activation of the NF- $\mathrm{kB}$ pathway, destabilizing HIF1a, and suppresses activation of Jmjd3 while promoting further fatty-acid oxidation to fuel OXPHOS [86,87]. Interestingly, M1 macrophage polarization via LPS+INF- $\gamma$ results in reduced mitochondrial mass compared to M2 polarization via IL-4, potentially through incurred mitochondrial damage [88]. These observations suggest increased mitochondrial damage is associated with macrophage inflammatory activation. In contrast, during times of low glucose availability, upregulation of ATP production by OXPHOS may preserve inflammatory and immune functions $[89,90]$.

\section{MITOCHONDRIAL DYNAMICS}

Macrophage responsiveness is reliant upon mitochondria function. Damaged mitochondria may result in a compromised immune response, disturbed ROS production, and/or senescence [91-93]. Partially damaged mitochondria can undergo fission to remove dysfunctional components or fusion to buffer transient mitochondrial defects [94]. The central regulators of fission and fusion are DRP1 and OPA1, MFN1, and MFN2 respectively [95-99]. Mitochondrial fission serves to remove damaged mitochondria that may aberrantly generate ROS, while fusion also serves to preserve and share mtDNA throughout the network. Mitochondria dynamically undergo fission and fusion to remove dysfunctional mitochondria while preserving functional aspects.

More severe mitochondrial damage may necessitate its removal. Mitophagy is the organelle-specific degradation of mitochondria that removes damaged or superfluous mitochondria. The most well-studied mitophagy pathway is ubiquitin-dependent PINK1-PRKN/PRK2. Briefly, increased ROS and loss of the $\Delta \Psi \mathrm{m}$ results in PINK1 stabilization on the 
OMM, ubiquination, recruitment of E3 ligases PRKN/PRKN2 [100-104], and activation of ATGs [105]. Mitophagy may play a critical role in attenuating inflammatory responses. Endogenous and exogenous cellular danger signals such as ROS, TLR signaling, or mtDNA activation can serve to prime and activate the NLRP3 inflammasome and IL-1 $\beta$ secretion. Supporting this notion, inhibition of mitophagy proteins ATG15 or PRKN leads to increased IL-1 $\beta$ secretion following LPS stimulation [106-109]. Conversely, induction of mitophagy via ULK1 eliminates $\Delta \Psi \mathrm{m}$ depolarization and mtROS to reduce caspase- 1 activation and IL-1 $\beta$ secretion [110,111]. As such, mitophagy may be considered to control inflammation, as dysfunctional mitochondria are removed to minimize incidental inflammatory stimulation. As mitophagy is impaired with age, its dysregulation likely contributes to inflammaging, and this has been associated with several age-related diseases including cardiovascular disease and sarcopenia [112-114]. A schematic of mitochondrial dynamics is shown in Figure 1.



Figure 1. The mitochondrial lifecycle. Fused mitochondria undergo fission through Fis1. Individual mitochondria can undergo fusion through the actions of Drp1, Opa1, Mfn1, and Mfn2, or can be shuttled to the mitophagy pathway via PINK1 and Parkin. Cellular senescence inhibits mitophagy to induce mitochondrial dysfunction.

\section{INTER-ORGANELLE CROSSTALK}

Mitochondrial dysfunction extends towards interactions with other organelles, so it is also important to consider their relationship during inflammaging. Mitochondria can migrate towards lysosomes for ion and metabolite transfer and to aid in inflammatory processes such as phagosome breakdown [115,116]. Chronic mitochondrial stress, which occurs during inflammaging, can impair lysosomal functions [117,118]. Lysosomal impairment leads to an accumulation of lipofuscin which can further dysregulate mitochondrial functions, including impaired 
mitophagy, increased ROS production, and reduced ATP generation [119]. Crosstalk between the ER and mitochondria also play an important role in aging. The ER is involved in protein synthesis and folding, and interaction between the ER and mitochondrial associated membranes regulates cellular $\mathrm{Ca}^{2+}[120,121]$. ER stress triggers the unfolded protein response (UPR) to alleviate the protein burden and prevent misfolding, and chronic UPR activation by garbage in the inflammaging environment can lead to impaired proteostasis and acceleration of age-related diseases [122].

\section{MITOCHONDRIAL DYSFUNCTION AND CELLULAR SENESCENCE}

Cellular senescence is a generally irreversible state of stable growtharrest in proliferative cells which is resistant to apoptosis and is accompanied by phenotypic changes that contribute to aging. Senescence was originally demonstrated to occur to human fibroblasts in culture after repeated passaging [123], which is now known to be due to telomere attrition [124]. This has since been shown to occur in multiple cell types including in post-mitotic cells, as a result of exposure to various stressors [125,126]. Senescence does have beneficial roles as it can prevent the spread of (and stimulate immune cells to remove) malignant cells [127], and it is also involved in embryonic development and wound healing [128,129]. However, the number of senescent cells (SCs) accumulate with age in multiple tissues [126] and has been causally implicated in agerelated dysfunction [130]. Senescence has thus been proposed to have evolved as a form of antagonistic pleiotropy, being beneficial to survival in young age, but detrimental in older age, with species-specific selection pressures driving a balance between tissue repair on the one hand and tumor suppression on the other [131].

SCs impart their effects through their senescence-associated secretory phenotype (SASP), which is characterized by an upregulation and secretion of proinflammatory cytokines, chemokines, exosomes, and other biological modulators which have autocrine, paracrine and systemic effects [132]. The primary role of the SASP within younger individuals may be to prevent the spread of damaged, senescent, or oncogenic cells by signaling to the immune system for clearance, but during aging, cellular damage accumulation may cause SC abundance to exceed the capacity for clearance by the immune system [127,133]. In conjunction, immune dysfunction caused by aging and senescence can reduce the ability of immune cells to clear SCs, further amplifying the accumulation of SCs with age [127]. There appears to be a threshold number of SCs above which agerelated pathologies result, and this generally occurs around the ages of 60 70 years in humans [130]. SC accumulation promotes pathology on multiple levels. SCs contribute to inflammaging [134], can cause chronic damage to tissues and impair their normal physiological functions, and likely contribute to immune dysfunction [127].

During aging and senescence, the regulatory mechanisms governing mitochondrial quality are reduced. These changes are summarized in 
Table 1. Mitophagy and fission, as observed by a decrease in DRP1 and FIS1, are reduced during aging and mitochondria appear in hyper-fused states [135-137]. Senescent and aged cells display a decreased $\Delta \Psi \mathrm{m}$, increased proton leakage, aberrant ROS generation, and an increase in TCA intermediates [91,92,135,138]. These defects in cellular energy generation likely play a role in aberrant cytokine production and reduced immune competence. Furthermore, depletion of mitochondria via PINK1/Parkin induction eliminates the SASP [139]. While an extreme model that also resulted in cell cycle arrest, these data highlight a central role for mitochondria in cellular senescence. Thus, interventional strategies directed at restoring the mechanisms governing mitochondrial maintenance may serve as effective in combating the SASP and inflammaging. For instance, dysfunctional mitochondria in SCs were shown to drive formation of cytosolic chromatin fragments (CCFs) and the SASP via a ROS-JNK retrograde signaling pathway. Restoration of mitochondrial function via low-dose pharmaceutical class I and II histone deacetylase inhibitors (HDACi) were shown to suppress the SASP and formation of CCFs, while higher dosages were found to have senolytic activity [140]. A proposed mechanism for this effect is that the HDACi upregulate nuclear-encoded OXPHOS genes and suppress oxidative stress from ROS, although HDACi may also restore mitochondrial function by other means such as enhanced mitophagy [140]. Regardless, restoration of mitochondrial function through pharmacological or lifestyle interventions may present an effective strategy for reducing the harmful effects caused by SCs and may also serve as a preventative measure of SC accumulation with age.

Table 1. Summary of age-related mitochondrial dysfunction.

\begin{tabular}{ll}
\hline Phenomenon & Aging Effect \\
\hline mtDNA release & $\uparrow$ \\
\hline Mitophagy & $\downarrow$ \\
\hline Fission & $\downarrow$ \\
\hline Fusion & $\uparrow$ \\
\hline$\Delta$ Im & $\downarrow$ \\
\hline Proton leak & $\uparrow$ \\
\hline mtROS production & $\uparrow$ \\
\hline
\end{tabular}

$\triangle \Psi$ m: mitochondrial membrane potential. mtDNA: mitochondrial DNA. mtROS: mitochondrial reactive oxygen species. 


\section{MACROPHAGE NAD BIOSYNTHESIS AND CONSUMPTION}

NAD plays key roles in biological processes and has become of major interest in the aging field. Declining NAD levels with age have been documented in most tissue and cell types, including macrophages [141], and this is linked with aging and its associated diseases [142]. NAD is a coenzyme mediating many redox reactions crucial to metabolism and is also an essential cofactor for several NAD-consuming enzymes implicated with aging, including sirtuins (SIRTs), poly-ADP-ribose polymerases (PARPs), and CD38 [142]. NAD can be obtained from tryptophan via the de novo biosynthesis pathway, also called the kynurenine pathway (KP), nicotinic acid (NA) through the Preiss-Handler pathway, and recycling from nicotinamide (NAM) via the salvage pathway [143]. The NAD precursors nicotinamide mononucleotide (NMN) and nicotinamide riboside (NR), which is converted into NMN, can also contribute to NAD production through the salvage pathway and are increasingly being used as an exogenous method to raise NAD levels, as they have better bioavailability than NA [144,145]. NAD decline with age has been proposed to be caused by reduced synthesis, recycling, and/or increased consumption of it [146]. However, plasma levels of NAD precursors like NA and NAM were recently shown to remain stable with age, though plasma NAD levels were drastically reduced, which suggests NAD decline may be primarily due to an increase in the activity of NAD-consuming enzymes [147].

The majority of intracellular NAD in most cell types is thought to be obtained via the salvage pathway [148], although the relative contribution of each pathway to NAD levels in macrophages is currently unknown. Further, recent studies have reported conflicting data as to the primary sources of NAD in macrophages, and the main NAD-consuming enzymes which cause it to decline [37,141,149]. It is likely dependent on the type of macrophage studied, whether it has been polarized to an inflammatory state, the organism it was derived from and its age, or a number of other factors. The majority of de novo NAD synthesis was shown to primarily occur in the liver, which excretes NAM for use in other tissues [148], although Minhas et al. recently showed that macrophages also rely on de novo NAD synthesis, and the activity of this pathway decreases with age and causes macrophage dysfunction [37]. The salvage pathway (Figure 2) appears to be the major contributor to NAD production in macrophages after inflammatory insults, and the rate limiting enzyme of this pathway, NAMPT, has been shown to be induced by TNFa, IL-1 $\beta$, LPS, IFN $\gamma$, and hypoxia, all of which increase with age [141,149,150]. NAMPT is likely induced in inflammatory macrophages to keep up with NAD demand due to increased expression of the NAD-consuming enzyme CD38, which also degrades NMN and thus may reduce the effectiveness of NAD-replacement therapies [141,151]. 


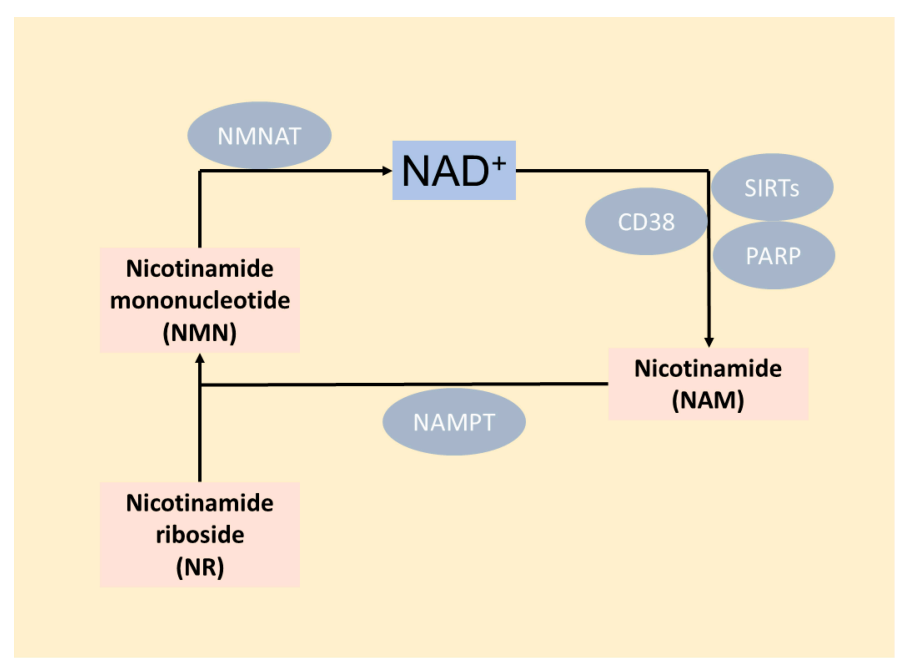

Figure 2. NAD salvage pathway.

While the salvage pathway is likely the primary contributor to NAD production in activated M1 macrophages, the de novo pathway may play a significant role during resting conditions. Minhas et al. recently demonstrated that the de novo pathway accounts for $40 \%$ of basal NAD production in human monocyte-derived macrophages (hMDMs). Additionally, they showed that inhibition of IDO1, which catalyzes the first step in the de novo pathway, altered mitochondrial morphology, suppressed OCR, and increased glycolytic activity [37]. Inhibition of QPRT, which is downstream of IDO1 in the de novo pathway, caused similar changes to mitochondrial morphology and metabolism, led to increased proinflammatory factors, and impaired phagocytosis. QPRT converts quinolinic acid into nicotinic acid mononucleotide (NAMN) which is ultimately converted into NAD. Aged hMDMs showed a significant decline in QPRT expression, de novo NAD synthesis, and SIRT3 activity, with increased polarization towards a proinflammatory state. Overexpressing QPRT, or supplementing with NMN, reversed these effects [37].

\section{AGE-RELATED NAD DECLINE: ROLE OF CD38 ACTIVATION IN MACROPHAGES}

CD38 is a transmembrane protein involved in $\mathrm{Ca}^{2+}$ signaling and mobilization and mediates signal transduction, cell adhesion, activation, proliferation and differentiation, and has been found in nearly every cell type examined [152-154]. CD38 is necessary for effective immune responses, as CD38 deficient mice have increased susceptibility to infections [155]. CD38 is active both intra- and extracellularly and was originally thought to work primarily extracellularly, but recent evidence suggests the majority of CD38 activity is intracellular in macrophages, with its primary function being the generation of cyclic ADP-ribose and NAADP for $\mathrm{Ca}^{2+}$ regulation [141,153].

CD38 expression increases in multiple tissue types with age, significantly contributes to NAD decline, and may be caused exclusively 
by activation of tissue-resident macrophages from the SASP and inflammaging environment [141,151]. In particular, TNFa, IL-10, and IL-6, as well as numerous PAMP TLR ligands including LPS, were each individually shown by Covarrubias et al. to significantly upregulate CD38 expression in M1 polarized macrophages, but not M2 or M0 [141,154,155]. Macrophages cultured in media from senescent fibroblast or preadipocyte cells also markedly upregulated CD38, but they did not significantly upregulate other NAD-consuming enzymes such as PARPs or SIRTs [141]. The senescent fibroblasts and preadipocyte cells themselves did not show significant upregulation in CD38 expression. Further, intraperitoneal (IP) injection of the drug doxorubicin, which induces senescence, caused an accumulation of $\mathrm{CD} 8^{+}$macrophages in white adipose and liver tissue, with an increase in senescent markers and proinflammatory cytokines, similar to that observed with aging [141]. Indeed, tissue-resident macrophages of the liver (Kupffer cells) accumulate with age, express greater amounts of CD38, show more signs of senescence, and are skewed towards a proinflammatory polarization [141]. Other immune populations in the liver and hepatocytes showed low CD38 expression. Endothelial cells were the only other population in the liver other than Kupffer cells which highly expressed CD38, but they showed only a marginal increase in CD38 expression with age [141]. Therefore, this evidence suggests macrophages may be primarily responsible for the age-related increase in CD38 expression and NAD decline seen in tissues with aging.

NAD decline caused by CD38 activation likely contributes to age-related pathologies on multiple levels. Overexpression of CD38, but not SIRT1 or PARP1, was shown to have detrimental impacts on mitochondrial function and morphology, causing a dramatic decrease in total respiratory capacity, mitochondrial-driven ATP synthesis, NAD levels, and oxygen consumption rate (OCR) [151]. These defects may be due in part to reduced NAD availability for SIRTs, especially the mitochondrial protein SIRT3, which is essential for mitochondrial metabolism and function [151,156]. We previously showed that classical monocytes from older adults have reduced respiratory capacity [157] and hypothesize that declining NAD levels as a result of activation of CD38 by the SASP may be a key contributing factor. Interestingly, the first successful intervention reported to reduce epigenetic age in humans showed that diminishing $\mathrm{CD}^{2} 8^{+}$monocyte concentrations, as a result of the intervention, correlated with reduced epigenetic age, and they hypothesized that a subsequent increase in NAD tissue availability may have been largely responsible [158]. Although CD38 activity in monocytes is understudied, it is known that most classical and intermediate monocytes express it, as it plays an important role in extravasation of monocytes into tissues [155]. While a fewer percentage of nonclassical monocytes express CD38, a minority of them were shown to highly express it and were associated with inflammatory disease activity [155]. As nonclassical monocytes increase with aging [157], are more prone to senescence than the other subsets [159], and senescence 
has been shown to increase CD38 expression in macrophages, senescent nonclassical monocytes may also contribute to NAD decline seen with aging both in tissues and in circulation.

Besides being activated by the inflammaging environment, CD38 may also contribute to it, as overexpression promotes IL-1 $\beta$, IL-6, IL-12, and glycolytic activity in hMDMs, and CD38 knockout (KO) mice have preserved mitochondrial function, SIRT3 activity, and were protected from NAD decline with age [155]. Although there is scant evidence on the interaction between CD38 and NF- $\kappa B, C D 38$ activation may increase NF- $\kappa B$ signaling. NF- $\kappa B$ is likely the primary transcription factor involved in the appearance of the SASP, and most of the proinflammatory genes expressed in senescent cells require it $[132,160]$. Therefore, it is of little surprise that NF- $\kappa B$ can activate CD38 [161], though recent evidence suggests CD38 may further amplify NF- $\kappa \mathrm{B}$ signaling. CD38 KO mice were found to have greatly diminished NF- $\kappa B$ signaling in an autoimmune arthritic mouse model [162]. Further, inhibition of CD38 by the senolytic flavonoid quercetin was shown to reduce NF- $\kappa \mathrm{B}$ signaling and M1 macrophage polarization in kidney and spleen tissue following IP LPS administration [154]. Since CD38 degrades NAD and NMN, inhibition with quercetin, when used in conjunction with NMN or NR therapy may be a viable method for increasing NAD levels, reducing proinflammatory macrophage polarization and senescence, and improving age-related pathologies.

As PARP1 and SIRT1 levels were found to decrease in several tissues with aging, CD38 is likely the main NAD-consuming enzyme contributing to age-related NAD decline [151], though the role PARPs play is inconclusive due to the abundance of contradictory findings in the literature. There is evidence for PARP1 both contributing to aging pathologies on the one hand by reducing NAD levels, and as a longevitypromoter on the other, and we recommend several review articles for more information [163,164]. PARP1 activity in macrophages specifically may contribute to inflammaging as it has been demonstrated to promote NF-KB and HMGB1 activity following LPS-stimulation [165,166]. Further, PARP1 inhibition has been shown to have anti-inflammatory effects [167]. While Covarrubias et al. reported no significant upregulation in PARP expression from senescent media, or following LPS administration in mice (though there was a trend upwards) [141], Cameron et al. found that LPS acutely caused ROS generation and DNA damage in BMDM, which stimulated PARP activity and led to NAMPT activation to keep up with NAD demand [37]. Like Covarrubias et al., they did not find an increase in enzymes of the Preiss-Handler or de novo pathway, and inhibiting NAMPT with FK866 led to a significant suppression in NAD levels in M1 macrophages, but not M0 or M2 [141,149]. Further, NAMPT inhibition diminished glycolytic activity and inflammatory mediators in M1 macrophages in vitro due to decreased GAPDH activity, which is NAD dependent [149]. This suggests NAD and NAMPT play critical roles during 
inflammatory activation in macrophages. The discrepancy between these two studies in PARP expression in M1 macrophages following LPSstimulation may be due to the time point of analysis. It may be that early decreases in NAD macrophage concentrations after LPS-stimulation are due to oxidative stress and resulting PARP activation, whereas ongoing chronic depletion may be due to increased CD38 expression resulting from the inflammaging environment [141,149].

Table 2 contains an overview of major findings discussed above.

Table 2. Macrophages, CD38, and nad metabolism.

\begin{tabular}{|c|c|c|c|c|}
\hline Species & Cell Type & Stimulus/Condition & Effect & Reference \\
\hline C57BL/6J mice & BMDM & Cytokines, TLR ligands & $\uparrow \mathrm{CD} 38$ & [141] \\
\hline C57BL/6J mice & WAT m $\phi$ & LPS & $\begin{array}{l}\uparrow \mathrm{CD} 38 \\
\uparrow \mathrm{TNFa}, \mathrm{IL}-1 \beta \\
\uparrow \mathrm{m} \phi\end{array}$ & [141] \\
\hline C57BL/6J mice & BMDM & Senescent media & $\uparrow \mathrm{CD} 38$ & [141] \\
\hline C57BL/6J mice & Liver and WAT m $\phi$ & Doxorubicin & $\uparrow \mathrm{CD} 38^{+} \mathrm{m} \phi$ & [141] \\
\hline C57BL/6J mice & Kupffer cells & $\begin{array}{l}\text { Aging (25 months old } \\
\text { compared to } 6 \text { months) }\end{array}$ & $\begin{array}{l}\uparrow \mathrm{CD} 38, \mathrm{p} 21, \mathrm{NAMPT}, \\
\text { IL-1 } \beta \text {, IL-18, CCL2, } \\
\text { HMGB1 } \\
\uparrow \mathrm{m} \phi \\
\uparrow \mathrm{M} 1 \text { polarization }\end{array}$ & [141] \\
\hline $\begin{array}{l}\text { Human (cell } \\
\text { line) }\end{array}$ & HEK293T & CD38 overexpression & $\begin{array}{l}\downarrow \text { mitochondrial } \\
\text { respiratory capacity } \\
\downarrow \text { NAD } \\
\text { Abnormal } \\
\text { mitochondrial } \\
\text { morphology }\end{array}$ & [151] \\
\hline C57BL/6 mice & $\begin{array}{l}\text { Isolated liver } \\
\text { mitochondria }\end{array}$ & CD38 KO vs WT & $\begin{array}{l}\uparrow \text { respiratory rate } \\
\uparrow \mathrm{NAD} \text { and NAD/NADH } \\
\uparrow \mathrm{SIRT} 3\end{array}$ & [151] \\
\hline Human & Monocytes & $\begin{array}{l}\text { Epigenetic age reversal } \\
\text { intervention }\end{array}$ & $\downarrow \mathrm{CD}^{2} 8^{+}$monocytes & [158] \\
\hline $\begin{array}{l}\text { Human (cell } \\
\text { line) }\end{array}$ & THP-1, U937 & LPS + IFN $\gamma$ & $\uparrow \mathrm{CD} 38$ vs $\mathrm{M} 0$ or $\mathrm{M} 2$ & [155] \\
\hline $\begin{array}{l}\text { Human (cell } \\
\text { line) }\end{array}$ & THP-1, U937 & $\begin{array}{l}\text { CD38 inhibition via } \\
\text { apigenin or rhein in M1 } \\
(\mathrm{LPS}+\mathrm{IFN} \gamma)\end{array}$ & $\downarrow$ IL-6, IL-12p40 & [155] \\
\hline C57BL/6 mice & BMDC & $\begin{array}{l}\text { CD38 KO vs WT with } \\
\text { collagen-induced } \\
\text { arthritis }\end{array}$ & $\begin{array}{l}\downarrow \text { phospho-NFkB } \\
\downarrow \text { IL-1 } \beta, \text { IL-4, IL-10 }\end{array}$ & [162] \\
\hline
\end{tabular}


Table 2. Cont.

\begin{tabular}{|c|c|c|c|c|}
\hline Species & Cell Type & Stimulus/Condition & Effect & Reference \\
\hline $\begin{array}{ll}\text { Mouse } & \text { (cell } \\
\text { line) } & \\
\end{array}$ & RAW 264.7 & LPS & CD38 activation & [154] \\
\hline $\begin{array}{l}\text { Mouse } \quad \text { (cell } \\
\text { line) }\end{array}$ & RAW 264.7 & $\begin{array}{l}\text { LPS stimulation with } \\
\text { CD38 inhibition via } \\
\text { quercetin }\end{array}$ & $\begin{array}{l}\downarrow \text { phospho-NFkB } \\
\downarrow \text { M1 polarization }\end{array}$ & [154] \\
\hline C57BL/6 mice & Kidney m $\phi$ & $\begin{array}{l}\text { LPS stimulation with } \\
\text { CD38 inhibition via } \\
\text { quercetin }\end{array}$ & $\begin{array}{l}\downarrow \text { m } \phi \text { accumulation } \\
\downarrow \text { CCL2 and TNFa } \\
\downarrow \text { M1 polarization } \\
\downarrow \text { phospho-NF-kB }\end{array}$ & [154] \\
\hline
\end{tabular}

BMDC: bone marrow-derived dendritic cells; BMDM: bone marrow-derived macrophages, CD: cluster of differentiation; IFN: interferon; IL: interleukin; KO: knockout; LPS: lipopolysaccharide; WAT: white adipose tissue; WT: wildtype.

\section{CONCLUSION}

Figure 3 outlines the major themes of this review. Accumulation of damage over time increases the number of DAMPs and PAMPs in circulation which seem to drive metabolic-dependent epigenetic changes that alter macrophage functions during aging. Among these alterations is a heightened basal state of inflammation, diminished or hyperactive inflammatory responses, and impaired effector functions. A significant number of DAMPs are derived from malfunctioning mitochondria. With age mitochondrial dynamics, mitophagy, and inter-organelle crosstalk are impaired leading to enhanced oxidative stress, mtDNA excretion, altered metabolism, and impaired proteostasis. Agie-related NAD decline plays a major role in mitochondrial dysfunction and new evidence suggests this decline may be largely due to an upregulation of CD38 in tissue-resident macrophages caused by the SASP, PAMPs, and other proinflammatory factors in the inflammaging environment. CD38 activation in monocytes may also play a significant role in NAD decline, but other immune cells such as lymphocytes and neutrophils do not seem to be a major contributor. Recently, there has been an ever-increasing amount of evidence demonstrating NAD supplementation to be effective in protecting against age-related pathologies [168]. The results reviewed here indicate that inhibition of CD38 in conjunction with NAD supplementation may be more effective than NAD supplementation alone as CD38 degrades both NAD and NMN. 




Figure 3. Schematic of an aging macrophage. Stimulation of the macrophage by SASP constituents, PAMPs, and DAMPs leads to intracellular signaling and propagation of the inflammatory state. Senescenceassociated mitochondrial dysfunction, including increased ROS production and mitochondrial mass, mitochondrial hyperfusion, and decreased membrane potential, may also play a role in immunometabolic changes in aging macrophages. Finally, CD38 expression increases consumption of NAD through the salvage pathway, leading to lower tissue levels of NAD.

\section{AUTHOR CONTRIBUTIONS}

JY and BP outlined the paper. JY, RE, BP wrote the paper. JY and BP edited and revised the paper. All authors approved the final submission.

\section{CONFLICTS OF INTEREST}

The authors declare that they have no conflicts of interest.

\section{FUNDING}

This work was supported by American Heart Association grants 18AIREA33960189 and 19TPA34910232 to BP.

\section{ACKNOWLEDGMENTS}

The authors would like to acknowledge Christopher Branner and Ian Russell for their valuable input.

\section{REFERENCES}

1. Kennedy BK, Berger SL, Brunet A, Campisi J, Cuervo AM, Epel ES, et al. Geroscience: Linking aging to chronic disease. Cell. 2014;159(4):709-13. https://doi.org/10.1016/j.cell.2014.10.039

2. Roth GA, Abate D, Abate KH, Abay SM, Abbafati C, Abbasi N, et al. Global, regional, and national age-sex-specific mortality for 282 causes of death in 195 countries and territories, 1980-2017: a systematic analysis for the Global Burden of Disease Study 2017. Lancet. 2018;392(10159):1736-88. https://doi.org/10.1016/S0140-6736(18)32203-7 
3. Fulop T, Larbi A, Dupuis G, Page ALe, Frost EH, Cohen AA, et al. Immunosenescence and inflamm-aging as two sides of the same coin: Friends or foes? Front Immunol. 2018;8:1960. https://doi.org/10.3389/fimmu.2017.01960

4. Franceschi C, Bonafe M, Valensin S, Olivieri F, De Luca M, Ottaviani E, et al. Inflamm-aging: An evoluationar pespective on immunosenescence. Ann N Y Acad Sci. 2006;908(1):244-54. https://doi.org/10.1111/j.1749-6632.200.tb06651.x

5. López-Otín C, Blasco MA, Partridge L, Serrano M, Kroemer G. The hallmarks of aging. Cell. 2013;153(6):1194-217. https://doi.org/10.1016/j.cell.2013.05.039

6. Franceschi C, Garagnani P, Vitale G, Capri M, Salvioli S. Inflammaging and “garb-aging”. Trends Endocrinol Metab. 2017;28(3):199-212. https://doi.org/10.1016/j.tem.2016.09.005

7. Thevaranjan N, Puchta A, Schulz C, Naidoo A, Szamosi JC, Verschoor CP, et al. Age-associated microbial dysbiosis promotes intestinal permeability, systemic inflammation, and macrophage dysfunction. Cell Host Microbe. 2017;21(4):455-66.e4. https://doi.org/10.1016/j.chom.2017.03.002

8. Bouchlaka MN, Sckisel GD, Chen M, Mirsoian A, Zamora AE, Maverakis E, et al. Aging predisposes to acute inflammatory induced pathology after tumor immunotherapy. J Exp Med. 2013;210(11):2223-37. https://doi.org/10.1084/jem.20131219

9. Yuan X, Klein D, Kerscher S, West BL, Weis J, Katona I, et al. Macrophage depletion ameliorates peripheral neuropathy in aging mice. J Neurosci. 2018;38(19):4610-20. https://doi.org/10.1523/JNEUROSCI.3030-17.2018

10. Woodcock KJ, Kierdorf K, Pouchelon CA, Vivancos V, Dionne MS, Geissmann F. Macrophage-derived UPD3 cytokine causes impaired glucose homeostasis and reduced lifespan in Drosophila fed a lipid-rich diet. Immunity. 2015;42(1):133-44. https://doi.org/10.1016/j.immuni.2014.12.023

11. Duong L, Radley-Crabb HG, Gardner JK, Tomay F, Dye DE, Grounds MD, et al. Macrophage depletion in elderly mice improves response to tumor immunotherapy, increases anti-tumor $\mathrm{T}$ cell activity and reduces treatmentinduced cachexia. Front Genet. 2018;9:1-14. https://doi.org/10.3389/fgene.2018.00526

12. Murray PJ, Allen JE, Biswas SK, Fisher EA, Gilroy DW, Goerdt S, et al. Macrophage activation and polarization: Nomenclature and experimental guidelines. Immunity. 2014;41(1):14-20. https://doi.org/10.1016/j.immuni.2014.06.008

13. Rea IM, Gibson DS, McGilligan V, McNerlan SE, Alexander HD, Ross OA. Age and age-related diseases: Role of inflammation triggers and cytokines. Front Immunol. 2018;9:1-28. https://doi.org/10.3389/fimmu.2018.00586

14. Xia S, Zhang X, Zheng S, Khanabdali R, Kalionis B, Wu J, et al. An update on inflamm-aging: Mechanisms, prevention, and treatment. J Immunol Res. 2016;2016:8426874. https://doi.org/10.1155/2016/8426874

15. Rőszer T. Understanding the mysterious M2 macrophage through activation markers and effector mechanisms. Mediators Inflamm. 2015;2015:1-16. https://doi.org/10.1155/2015/816460 
16. Xue J, Schmidt SV, Sander J, Draffehn A, Krebs W, Quester I, et al. Transcriptome-based network analysis reveals a spectrum model of human macrophage activation. Immunity. 2014;40(2):274-88. https://doi.org/10.1016/j.immuni.2014.01.006

17. Lavin Y, Winter D, Blecher-Gonen R, David E, Keren-Shaul H, Merad M, et al. Tissue-resident macrophage enhancer landscapes are shaped by the local microenvironment. Cell. https://doi.org/10.1016/j.cell.2014.11.018

18. Vogelpoel LTC, Hansen IS, Rispens T, Muller FJM, van Capel TMM, Turina MC, et al. Fc gamma receptor-TLR cross-talk elicits pro-inflammatory cytokine production by human M2 macrophages. Nat Commun. 2014;5(1):5444. https://doi.org/10.1038/ncomms6444

19. Cui C, Driscoll RK, Piao Y, Chia CW, Gorospe M, Ferrucci L. Skewed macrophage polarization in aging skeletal muscle. Aging Cell. 2019;18:313032. https://doi.org/10.1111/acel.13032

20. Hall BM, Balan V, Gleiberman AS, Strom E, Krasnov P, Virtuoso LP, et al. p16(Ink4a) and senescence-associated $\beta$-galactosidase can be induced in macrophages as part of a reversible response to physiological stimuli. Aging. 2017;9(8):1867-84. https://doi.org/10.18632/aging.101268

21. Jackaman C, Radley-Crabb HG, Soffe Z, Shavlakadze T, Grounds MD, Nelson DJ. Targeting macrophages rescues age-related immune deficiencies in C57BL/6J geriatric mice. Aging Cell. 2013;12(3):345-57. https://doi.org/10.1111/acel.12062

22. Hsieh S, Huang L, Chang Y, Hung C, Yang Y. M2b Macrophage subset decrement as an indicator of cognitive function in Alzheimer's disease. Psychiatry Clin Neurosci. 2020. https://doi.org/10.1111/pcn.13000

23. Gonzalez OA, Novak MJ, Kirakodu S, Stromberg A, Nagarajan R, Huang CB, et al. Differential gene expression profiles reflecting macrophage polarization in aging and periodontitis gingival tissues. Immunol Invest. 2015;44(7):643-64. https://doi.org/10.3109/08820139.2015.1070269

24. Kim O-H, Kim H, Kang J, Yang D, Kang Y-H, Lee DH, et al. Impaired phagocytosis of apoptotic cells causes accumulation of bone marrow-derived macrophages in aged mice. BMB Rep. 2017;50(1):43-8. https://doi.org/10.5483/BMBRep.2017.50.1.167

25. Anders CB, Lawton TMW, Smith H, Garret J, Ammons MCB. Metabolic immunomodulation, transcriptional regulation, and signal protein expression define the metabotype and effector functions of five polarized macrophage phenotypes. bioRxiv 985788 [Preprint]. 2020 Mar 11. https://doi.org/10.1101/2020.03.10.985788

26. Tang Y, Matsuoka I, Ono T, Inoue K, Kimura J. Selective up-regulation of P2X4receptor gene expression by interferon-gamma in vascular endothelial cells. J Pharmacol Sci. 2008;107(4):419-27. https://doi.org/JST.JSTAGE/jphs/08073FP

27. Hall BM, Balan V, Gleiberman AS, Strom E, Krasnov P, Virtuoso LP, et al. Aging of mice is associated with p16(Ink4a)- and $\beta$-galactosidase-positive macrophage accumulation that can be induced in young mice by senescent cells. Aging. 2016;8(7):1294-315. https://doi.org/10.18632/aging.100991 
28. van Beek AA, Van den Bossche J, Mastroberardino PG, de Winther MPJ, Leenen PJM. Metabolic alterations in aging macrophages: Ingredients for inflammaging? Trends Immunol. 2019;40(2):113-27. https://doi.org/10.1016/j.it.2018.12.007

29. Albright JM, Dunn RC, Shults JA, Boe DM, Afshar M, Kovacs EJ. Advanced age alters monocyte and macrophage responses. Antioxid Redox Signal. 2016;25(15):805-15. https://doi.org/10.1089/ars.2016.6691

30. Linehan E, Fitzgerald D. Ageing and the immune system: focus on macrophages. Eur J Microbiol Immunol. 2015;5(1):14-24. https://doi.org/10.1556/EuJMI-D-14-00035

31. Linehan E, Dombrowski Y, Snoddy R, Fallon PG, Kissenpfennig A, Fitzgerald DC. Aging impairs peritoneal but not bone marrow-derived macrophage phagocytosis. Aging Cell. 2014;13(4):699-708. https://doi.org/10.1111/acel.12223

32. Wong CK, Smith CA, Sakamoto K, Kaminski N, Koff JL, Goldstein DR. Aging impairs alveolar macrophage phagocytosis and increases influenza-induced mortality in mice. J Immunol. 2017;199(3):1060-8. https://doi.org/10.4049/jimmunol.1700397

33. Natrajan MS, de la Fuente AG, Crawford AH, Linehan E, Nuñez V, Johnson KR, et al. Retinoid X receptor activation reverses age-related deficiencies in myelin debris phagocytosis and remyelination. Brain. 2015;138(12):3581-97. https://doi.org/10.1093/brain/awv289

34. Mosher KI, Wyss-Coray T. Microglial dysfunction in brain aging and Alzheimer's disease. Biochem Pharmacol. 2014;88(4):594-604. https://doi.org/10.1016/j.bcp.2014.01.008

35. Ritzel RM, Doran SJ, Glaser EP, Meadows VE, Faden AI, Stoica BA, et al. Old age increases microglial senescence, exacerbates secondary neuroinflammation, and worsens neurological outcomes after acute traumatic brain injury in mice. Neurobiol Aging. 2019;77:194-206. https://doi.org/10.1016/j.neurobiolaging.2019.02.010

36. Stranks AJ, Hansen AL, Panse I, Mortensen M, Ferguson DJP, Puleston DJ, et al. Autophagy controls acquisition of aging features in macrophages. J Innate Immun. 2015;7(4):375-91. https://doi.org/10.1159/000370112

37. Minhas PS, Liu L, Moon PK, Joshi AU, Dove C, Mhatre S, et al. Macrophage de novo $\mathrm{NAD}^{+}$synthesis specifies immune function in aging and inflammation. Nat Immunol. 2019;20(1):50-63. https://doi.org/10.1038/s41590-018-0255-3

38. Chougnet CA, Thacker RI, Shehata HM, Hennies CM, Lehn MA, Lages CS, et al. Loss of phagocytic and antigen cross-presenting capacity in aging dendritic cells Is associated with mitochondrial dysfunction. J Immunol. 2015;195(6):2624-32. https://doi.org/10.4049/jimmunol.1501006

39. Park D, Han CZ, Elliott MR, Kinchen JM, Trampont PC, Das S, et al. Continued clearance of apoptotic cells critically depends on the phagocyte Ucp2 protein. Nature. 2011;477(7363):220-4. https://doi.org/10.1038/nature10340

40. Fulop T, Dupuis G, Baehl S, Le Page A, Bourgade K, Frost E, et al. From inflamm-aging to immune-paralysis: a slippery slope during aging for 
immune-adaptation.

Biogerontology.

2016;17(1):147-57.

https://doi.org/10.1007/s10522-015-9615-7

41. Kohut ML, Senchina DS, Madden KS, Martin AE, Felten DL, Moynihan JA. Age effects on macrophage function vary by tissue site, nature of stimulant, and exercise behavior. Exp Gerontol. 2004;39(9):1347-60. https://doi.org/10.1016/j.exger.2004.07.001

42. Barrett JP, Costello DA, O’Sullivan J, Cowley TR, Lynch MA. Bone marrowderived macrophages from aged rats are more responsive to inflammatory stimuli. J Neuroinflammation. 2015;12(1):67. https://doi.org/10.1186/s12974015-0287-7

43. Smallwood HS, López-Ferrer D, Squier TC. Aging enhances the production of reactive oxygen species and bactericidal activity in peritoneal macrophages by upregulating classical activation pathways. Biochemistry. 2011;50(45):9911-22. https://doi.org/10.1021/bi2011866

44. Gibon E, Loi F, Córdova LA, Pajarinen J, Lin T, Lu L, et al. Aging affects bone marrow macrophage polarization: Relevance to bone healing. Regen Eng Transl Med. 2016;2(2):98-104. https://doi.org/10.1007/s40883-016-0016-5

45. Franceschi C, Salvioli S, Garagnani P, de Eguileor M, Monti D, Capri M. Immunobiography and the heterogeneity of immune responses in the elderly: A focus on inflammaging and trained immunity. Front Immunol. 2017;8:982. https://doi.org/10.3389/fimmu.2017.00982

46. Cheng S-C, Quintin J, Cramer RA, Shepardson KM, Saeed S, Kumar V, et al. mTOR- and HIF-1 -mediated aerobic glycolysis as metabolic basis for trained immunity. Science. 2014;345(6204):1250684. https://doi.org/10.1126/science.1250684

47. Arts RJW, Novakovic B, ter Horst R, Carvalho A, Bekkering S, Lachmandas E, et al. Glutaminolysis and fumarate accumulation integrate immunometabolic and epigenetic programs in trained immunity. Cell Metab. 2016;24(6):807-19. https://doi.org/10.1016/j.cmet.2016.10.008

48. Van Tuijl J, Joosten LAB, Netea MG, Bekkering S, Riksen MP. Immunometabolism orchestrates training of innate immunity in atherosclerosis. Cardiovasc Res. 2019;115(9):1416-24. https://doi.org/10.1093/cvr/cvz107

49. Bauer M, Weis S, Netea MG, Wetzker R. Remembering pathogen dose: Longterm adaptation in innate immunity. Trends Immunol. 2018;39(6):438-45. https://doi.org/10.1016/j.it.2018.04.001

50. Renshaw M, Rockwell J, Engleman C, Gewirtz A, Katz J, Sambhara S. Cutting edge: Impaired toll-like receptor expression and function in aging. J Immunol. 2002;169(9):4697-701. https://doi.org/10.4049/jimmunol.169.9.4697

51. Fei F, Lee KM, McCarry BE, Bowdish DME. Age-associated metabolic dysregulation in bone marrow-derived macrophages stimulated with lipopolysaccharide. Sci Rep. 2016;6:22637. https://doi.org/10.1038/srep22637

52. Mahbub S, Deburghgraeve CR, Kovacs EJ. Advanced age impairs macrophage polarization. J Interf Cytokine Res. 2011;32(1):18-26. https://doi.org/10.1089/jir.2011.0058 
53. Gómez CR, Acuña-Castillo C, Nishimura S, Pérez V, Escobar A, Salazar-Onfray F, et al. Serum from aged F344 rats conditions the activation of young macrophages. Mech Ageing Dev. 2006;127(3):257-63. https://doi.org/10.1016/j.mad.2005.10.002

54. Boyd AR, Shivshankar P, Jiang S, Berton MT, Orihuela CJ. Age-related defects in TLR2 signaling diminish the cytokine response by alveolar macrophages during murine pneumococcal pneumonia. Exp Gerontol. 2012;47(7):507-18. https://doi.org/10.1016/j.exger.2012.04.004

55. Pence BD, Yarbro JR. Classical monocytes maintain ex vivo glycolytic metabolism and early but not later inflammatory responses in older adults. Immun Ageing. 2019;16:3.

56. Liu TF, Yoza BK, El Gazzar M, Vachharajani VT, McCall CE. NAD ${ }^{+}$-dependent SIRT1 deacetylase participates in epigenetic reprogramming during endotoxin tolerance. J Biol Chem. 2011;286(11):9856-64. https://doi.org/10.1074/jbc.M110.196790

57. Tao J, Zhang J, Ling Y, McCall CE, Liu TF. Mitochondrial sirtuin 4 resolves immune tolerance in monocytes by rebalancing glycolysis and glucose oxidation homeostasis. Front Immunol. 2018;9:419. https://doi.org/10.3389/fimmu.2018.00419

58. Chandel NS. Mitochondria as signaling organelles. BMC Biol. 2014;12(1):34. https://doi.org/10.1186/1741-7007-12-34

59. Madamanchi NR, Runge MS. Mitochondrial dysfunction in atherosclerosis. Circ Res. 2007;100(4):460-73. https://doi.org/10.1161/01.RES.0000258450.44413.96

60. Bratic A, Larsson NG. The role of mitochondria in aging. J Clin Invest. 2013;123(3):951-7. https://doi.org/10.1172/JCI64125

61. Bao D, Zhao J, Zhou X, Yang Q, Chen Y, Zhu J, et al. Mitochondrial fissioninduced mtDNA stress promotes tumor-associated macrophage infiltration and HCC progression. Oncogene. 2019;38(25):5007-20. https://doi.org/10.1038/s41388-019-0772-z

62. Thapa B, Lee K. Metabolic influence on macrophage polarization and pathogenesis. BMB Rep. 2019;52(6):360-72. https://doi.org/10.5483/BMBRep.2019.52.6.140

63. Harman D. Aging: A theory based on free radical and radiation chemistry. J Gerontol. 1956;11(3):298-300. https://doi.org/10.1093/geronj/11.3.298

64. Nilsson MI, Tarnopolsky MA. Mitochondria and aging - the role of exercise as a countermeasure. Biology. 2019;8(2):40. https://doi.org/10.3390/biology8020040

65. Carmona-Gutierrez D, Hughes AL, Madeo F, Ruckenstuhl C. The crucial impact of lysosomes in aging and longevity. Ageing Res Rev. 2016;32:2-12. https://doi.org/10.1016/j.arr.2016.04.009

66. Brown MK, Naidoo N. The endoplasmic reticulum stress response in aging and age-related diseases. Front Physiol. 2012;3:263. https://doi.org/10.3389/fphys.2012.00263

67. Rossignol R, Faustin B, Rocher C, Malgat M, Mazat J-P, Letellier T. Mitochondrial threshold effects. Biochem J. 2003;370(3):751-62. https://doi.org/10.1042/bj20021594 
68. Larsson NG, Tulinius MH, Holme E, Oldfors A, Andersen O, Wahlström J, et al. Segregation and manifestations of the mtDNA tRNA(Lys) A-->G(8344) mutation of myoclonus epilepsy and ragged-red fibers (MERRF) syndrome. Am J Hum Genet. 1992;51(6):1201-12.

69. Boulet L, Karpati G, Shoubridge EA. Distribution and threshold expression of the tRNA(Lys) mutation in skeletal muscle of patients with myoclonic epilepsy and ragged-red fibers (MERRF). Am J Hum Genet. 1992;51(6):1187-200.

70. Riley JS, Quarato G, Cloix C, Lopez J, O’Prey J, Pearson M, et al. Mitochondrial inner membrane permeabilisation enables mtDNA release during apoptosis. EMBO J. 2018;37(17):1-16. https://doi.org/10.15252/embj.201899238

71. Zhang Q, Itagaki K, Hauser CJ. Mitochondrial DNA is released by shock and activates neutrophils via p38 map kinase. Shock. 2010;34(1):55-9. https://doi.org/10.1097/SHK.0b013e3181cd8c08

72. Zhang Q, Raoof M, Chen Y, Sumi Y, Sursal T, Junger W, et al. Circulating mitochondrial DAMPs cause inflammatory responses to injury. Nature. 2010;464(7285):104-7. https://doi.org/10.1038/nature08780

73. Shimada K, Crother TR, Karlin J, Dagvadorj J, Chiba N, Chen S, et al. Oxidized mitochondrial DNA activates the NLRP3 inflammasome during apoptosis. Immunity. 2012;36(3):401-14. https://doi.org/10.1016/j.immuni.2012.01.009

74. Rongvaux A, Jackson R, Harman CCD, Li T, West AP, de Zoete MR, et al. Apoptotic caspases prevent the induction of type I interferons by mitochondrial DNA. Cell. 2014;159(7):1563-77. https://doi.org/10.1016/j.cell.2014.11.037

75. Oka T, Hikoso S, Yamaguchi O, Taneike M, Takeda T, Tamai T, et al. Mitochondrial DNA that escapes from autophagy causes inflammation and heart failure. Nature. 2012;485(7397):251-5. https://doi.org/10.1038/nature10992

76. Pinti M, Cevenini E, Nasi M, De Biasi S, Salvioli S, Monti D, et al. Circulating mitochondrial DNA increases with age and is a familiar trait: Implications for “inflamm-aging." Eur J Immunol. 2014;44(5):1552-62. https://doi.org/10.1002/eji.201343921

77. Verschoor CP, Loukov D, Naidoo A, Puchta A, Johnstone J, Millar J, et al. Circulating TNF and mitochondrial DNA are major determinants of neutrophil phenotype in the advanced-age, frail elderly. Mol Immunol. 2015;65(1):148-56. https://doi.org/10.1016/j.molimm.2015.01.015

78. Bonawitz ND, Clayton DA, Shadel GS. Initiation and beyond: Multiple functions of the human mitochondrial transcription machinery. Mol Cell. 2006;24(6):813-25. https://doi.org/10.1016/j.molcel.2006.11.024

79. Calvo SE, Mootha VK. The mitochondrial proteome and human disease. Annu Rev Genomics Hum Genet. 2010;11(1):25-44. https://doi.org/10.1146/annurevgenom-082509-141720

80. Wolf DM, Segawa M, Kondadi AK, Anand R, Bailey ST, Reichert AS, et al. Individual cristae within the same mitochondrion display different membrane potentials and are functionally independent. EMBO J. 2019;38(22):e101056. https://doi.org/10.15252/embj.2018101056 
81. Zhao RZ, Jiang S, Zhang L, Yu ZB. Mitochondrial electron transport chain, ROS generation and uncoupling. Int J Mol Med. 2019;44(1):3-15. https://doi.org/10.3892/ijmm.2019.4188

82. Wong HS, Dighe PA, Mezera V, Monternier PA, Brand MD. Production of superoxide and hydrogen peroxide from specific mitochondrial sites under different bioenergetic conditions. J Biol Chem. 2017;292(41):16804-9. https://doi.org/10.1074/jbc.R117.789271

83. Garedew A, Henderson SO, Moncada S. Activated macrophages utilize glycolytic ATP to maintain mitochondrial membrane potential and prevent apoptotic cell death. Cell Death Differ. 2010;17(10):1540-50. https://doi.org/10.1038/cdd.2010.27

84. Geng J, Sun X, Wang P, Zhang S, Wang X, Wu H, et al. Kinases Mst1 and Mst2 positively regulate phagocytic induction of reactive oxygen species and bactericidal activity. Nat Immunol. 2015;16(11):1142-52. https://doi.org/10.1038/ni.3268

85. Mills EL, Kelly B, Logan A, Costa ASH, Varma M, Bryant CE, et al. Succinate dehydrogenase supports metabolic repurposing of mitochondria to drive inflammatory macrophages. Cell. 2016;167(2):457-70.e13. https://doi.org/10.1016/j.cell.2016.08.064

86. Kruidenier L, Chung C, Cheng Z, Liddle J, Che K, Joberty G, et al. A selective jumonji H3K27 demethylase inhibitor modulates the proinflammatory macrophage $\quad$ response. Nature. 2012;488(7411):404-8. https://doi.org/10.1038/nature11262

87. Liu P, Wang H, Li X, Chao T, Teav T, Christen S, et al. a-ketoglutarate orchestrates macropShage activation through metabolic and epigenetic reprogramming. Nat Immunol. 2017;18(9):985-94. https://doi.org/10.1038/ni.3796

88. Esteban-Martínez L, Sierra-Filardi E, McGreal RS, Salazar-Roa M, Mariño G, Seco E, et al. Programmed mitophagy is essential for the glycolytic switch during cell differentiation. EMBO J. 2017;36(12):1688-706. https://doi.org/10.15252/embj.201695916

89. Raulien N, Friedrich K, Strobel S, Rubner S, Baumann S, von Bergen M, et al. Fatty acid oxidation compensates for lipopolysaccharide-induced Warburg effect in glucose-deprived monocytes. Front Immunol. 2017;8:609. https://doi.org/10.3389/fimmu.2017.00609

90. Yarbro JR, Pence BD. Classical monocytes from older adults maintain capacity for metabolic compensation during glucose deprivation and lipopolysaccharide stimulation. Mech Ageing Dev. 2019;183:111146. https://doi.org/10.1016/j.mad.2019.111146

91. Moiseeva O, Bourdeau V, Roux A, Deschênes-Simard X, Ferbeyre G. Mitochondrial dysfunction contributes to oncogene-induced senescence. Mol Cell Biol. 2009;29(16):4495-507. https://doi.org/10.1128/MCB.01868-08

92. Passos JF, Nelson G, Wang C, Richter T, Simillion C, Proctor CJ, et al. Feedback between p21 and reactive oxygen production is necessary for cell senescence. Mol Syst Biol. 2010;6(1):347. https://doi.org/10.1038/msb.2010.5 
93. Wiley CD, Velarde MC, Lecot P, Liu S, Sarnoski EA, Freund A, et al. Mitochondrial dysfunction induces senescence with a distinct secretory phenotype. Cell Metab. 2016;23(2):303-14. https://doi.org/10.1016/j.cmet.2015.11.011

94. Youle RJ, van der Bliek AM. Mitochondrial fission, fusion, and stress. Science. 2012;337(6098):1062-5. https://doi.org/10.1126/science.1219855

95. Westermann B. Mitochondrial fusion and fission in cell life and death. Nat Rev Mol Cell Biol. 2010;11(12):872-84. doi: 10.1038/nrm3013

96. Koshiba T, Detmer SA, Kaiser JT, Chen H, McCaffery JM, Chan DC. Structural basis of mitochondrial tethering by mitofusin complexes. Science. 2004;305(5685):858-62. https://doi.org/10.1126/science.1099793

97. Basu K, Lajoie D, Aumentado-Armstrong T, Chen J, Koning RI, Bossy B, et al. Molecular mechanism of DRP1 assembly studied in vitro by cryo-electron microscopy. PLoS One. 2017;12(6):e0179397. https://doi.org/10.1371/journal.pone.0179397

98. Francy CA, Alvarez FJD, Zhou L, Ramachandran R, Mears JA. The mechanoenzymatic core of dynamin-related protein 1 comprises the minimal machinery required for membrane constriction. J Biol Chem. 2015;290(18):11692-703. https://doi.org/10.1074/jbc.M114.610881

99. Song Z, Chen H, Fiket M, Alexander C, Chan DC. OPA1 processing controls mitochondrial fusion and is regulated by mRNA splicing, membrane potential, and Yme1L. J Cell Biol. 2007;178(5):749-55. https://doi.org/10.1083/jcb.200704110

100. Jin SM, Lazarou M, Wang C, Kane LA, Narendra DP, Youle RJ. Mitochondrial membrane potential regulates PINK1 import and proteolytic destabilization by PARL. J Cell Biol. 2010;191(5):933-42. https://doi.org/10.1083/jcb.201008084

101. Yamano K, Youle RJ. PINK1 is degraded through the N-end rule pathway. Autophagy. 2013;9(11):1758-69. https://doi.org/10.4161/auto.24633

102. Okatsu K, Oka T, Iguchi M, Imamura K, Kosako H, Tani N, et al. PINK1 autophosphorylation upon membrane potential dissipation is essential for Parkin recruitment to damaged mitochondria. Nat Commun. 2012;3(1):1016. https://doi.org/10.1038/ncomms2016

103. Koyano F, Okatsu K, Kosako H, Tamura Y, Go E, Kimura M, et al. Ubiquitin is phosphorylated by PINK1 to activate parkin. Nature. 2014;510(7503):162-6. https://doi.org/10.1038/nature13392

104. Bingol B, Tea JS, Phu L, Reichelt M, Bakalarski CE, Song Q, et al. The mitochondrial deubiquitinase USP30 opposes parkin-mediated mitophagy. Nature. 2014;510(7505):370-5. https://doi.org/10.1038/nature13418

105. Yoshii SR, Mizushima N. Autophagy machinery in the context of mammalian mitophagy. Biochim Biophys Acta. 2015;1853(10):2797-801. https://doi.org/10.1016/j.bbamcr.2015.01.013

106. Sliter DA, Martinez J, Hao L, Chen X, Sun N, Fischer TD, et al. Parkin and PINK1 mitigate STING-induced inflammation. Nature. 2018;561(7722):258-62. https://doi.org/10.1038/s41586-018-0448-9

107. Zhou R, Yazdi AS, Menu P, Tschopp J. A role for mitochondria in NLRP3 inflammasome activation. Nature. 2011;469(7329):221-6. https://doi.org/10.1038/nature09663 
108. Nakahira K, Haspel JA, Rathinam VAK, Lee S-J, Dolinay T, Lam HC, et al. Autophagy proteins regulate innate immune responses by inhibiting the release of mitochondrial DNA mediated by the NALP3 inflammasome. Nat Immunol. 2011;12(3):222-30. https://doi.org/10.1038/ni.1980

109. Zhong Z, Umemura A, Sanchez-Lopez E, Liang S, Shalapour S, Wong J, et al. NF$\kappa B$ restricts inflammasome activation via elimination of damaged mitochondria. Cell. 2016;164(5):896-910. https://doi.org/10.1016/j.cell.2015.12.057

110. He Y, She H, Zhang T, Xu H, Cheng L, Yepes M, et al. p38 MAPK inhibits autophagy and promotes microglial inflammatory responses by phosphorylating ULK1. J Cell Biol. 2018;217(1):315-28. https://doi.org/10.1083/jcb.201701049

111. Bachstetter AD, Xing B, de Almeida L, Dimayuga ER, Watterson DM, Van Eldik LJ. Microglial p38a MAPK is a key regulator of proinflammatory cytokine upregulation induced by toll-like receptor (TLR) ligands or beta-amyloid (A $\beta$ ). J Neuroinflammation. 2011;8:79. https://doi.org/10.1186/1742-2094-8-79

112. Sun N, Yun J, Liu J, Malide D, Liu C, Rovira II, et al. Measuring in vivo mitophagy. Mol Cell. 2015;60(4):685-96. https://doi.org/10.1016/j.molcel.2015.10.009

113. Sebastian D, Sorianello E, Segales J, Irazoki A, Ruiz-Bonilla V, Sala D, et al. Mfn2 deficiency links age-related sarcopenia and impaired autophagy to activation of an adaptive mitophagy pathway. EMBO J. 2016;35(15):1677-93. https://doi.org/10.15252/embj.201593084

114. Vásquez-Trincado C, García-Carvajal I, Pennanen C, Parra V, Hill JA, Rothermel BA, et al. Mitochondrial dynamics, mitophagy and cardiovascular disease. J Physiol. 2016;594(3):509-25. https://doi.org/10.1113/JP271301

115. Wong YC, Kim S, Peng W, Krainc D. Regulation and Function of MitochondriaLysosome Membrane Contact Sites in Cellular Homeostasis. Trends Cell Biol. 2019;29(6):500-13. https://doi.org/10.1016/j.tcb.2019.02.004

116. Todkar K, Ilamathi HS, Germain M. Mitochondria and lysosomes: Discovering bonds. Front Cell Dev Biol. 2017;5:106. https://doi.org/10.3389/fcell.2017.00106

117. Fernandez-Mosquera L, Yambire KF, Couto R, Pereyra L, Pabis K, Ponsford AH, et al. Mitochondrial respiratory chain deficiency inhibits lysosomal hydrolysis. Autophagy. 2019;15(9):1572-91. https://doi.org/10.1080/15548627.2019.1586256

118. Fernández-Mosquera L, Diogo CV, Yambire KF, Santos GL, Luna Sánchez M, Bénit $\mathrm{P}$, et al. Acute and chronic mitochondrial respiratory chain deficiency differentially regulate lysosomal biogenesis. Sci Rep. 2017;7(1):45076. https://doi.org/10.1038/srep45076

119. Terman A, Kurz T, Navratil M, Arriaga EA, Brunk UT. Mitochondrial turnover and aging of long-lived postmitotic cells: The mitochondrial-lysosomal axis theory of aging. Antioxid Redox Signal. 2010;12(4):503-35. https://doi.org/10.1089/ars.2009.2598

120. Estébanez B, de Paz JA, Cuevas MJ, González-Gallego J. Endoplasmic reticulum unfolded protein response, aging and exercise: An update. Front Physiol. 2018;9:1744. https://doi.org/10.3389/fphys.2018.01744

121. van Vliet AR, Agostinis P. Mitochondria-associated membranes and ER stress. Curr Top Microbiol Immunol. 2018;414:73-102. doi: 10.1007/82_2017_2 
122. Martínez G, Duran-Aniotz C, Cabral-Miranda F, Vivar JP, Hetz C. Endoplasmic reticulum proteostasis impairment in aging. Aging Cell. 2017;16(4):615-23. https://doi.org/10.1111/acel.12599

123. Hayflick L. The limited in vitro lifetime of human diploid cell strains. Exp Cell Res. 1965;37(3):614-36. https://doi.org/10.1016/0014-4827(65)90211-9

124. Bodnar AG. Extension of life-span by introduction of telomerase into normal human cells. Science. 1998;279(5349):349-52. https://doi.org/10.1126/science.279.5349.349

125. Sapieha P, Mallette FA. Cellular senescence in postmitotic cells: Beyond growth arrest. Trends Cell Biol. 2018;28(8):595-607. https://doi.org/10.1016/j.tcb.2018.03.003

126. Tuttle CSL, Waaijer MEC, Slee-Valentijn MS, Stijnen T, Westendorp R, Maier AB. Cellular senescence and chronological age in various human tissues: A systematic review and meta-analysis. Aging Cell. 2020;19(2):e13083. https://doi.org/10.1111/acel.13083

127. Prata LGPL, Ovsyannikova IG, Tchkonia T, Kirkland JL. Senescent cell clearance by the immune system: Emerging therapeutic opportunities. Semin Immunol. 2019;40:101275. https://doi.org/10.1016/j.smim.2019.04.003

128. Demaria M, Ohtani N, Youssef SA, Rodier F, Toussaint W, Mitchell JR, et al. An essential role for senescent cells in optimal wound healing through secretion of PDGF-AA. Dev Cell. 2014;31(6):722-33. https://doi.org/10.1016/j.devcel.2014.11.012

129. Muñoz-Espín D, Cañamero M, Maraver A, Gómez-López G, Contreras J, Murillo-Cuesta S, et al. Programmed cell senescence during mammalian embryonic development. Cell. 2013;155(5):1104-18. https://doi.org/10.1016/j.cell.2013.10.019

130. Tchkonia T, Kirkland JL. Aging, cell senescence, and chronic disease. JAMA. 2018;320(13):1319. https://doi.org/10.1001/jama.2018.12440

131. Weinstein BS, Ciszek D. The reserve-capacity hypothesis: evolutionary origins and modern implications of the trade-off between tumor-suppression and tissue-repair. Exp Gerontol. 2002;37(5):615-27. https://doi.org/10.1016/S05315565(02)00012-8

132. Lopes-Paciencia S, Saint-Germain E, Rowell M-C, Ruiz AF, Kalegari P, Ferbeyre G. The senescence-associated secretory phenotype and its regulation. Cytokine. 2019;117:15-22. https://doi.org/10.1016/j.cyto.2019.01.013

133. Dodig S, Čepelak I, Pavić I. Hallmarks of senescence and aging. Biochem Medica. 2019;29(3):1-15. https://doi.org/10.11613/BM.2019.030501

134. Franceschi C, Campisi J. Chronic inflammation (Inflammaging) and its potential contribution to age-associated diseases. J Gerontol A. 2014;69:S4-9. https://doi.org/10.1093/gerona/glu057

135. Passos JF, Saretzki G, Ahmed S, Nelson G, Richter T, Peters H, et al. Mitochondrial dysfunction accounts for the stochastic heterogeneity in telomere-dependent senescence. PLoS Biol. 2007;5(5):e110. https://doi.org/10.1371/journal.pbio.0050110

136. Mai S, Klinkenberg M, Auburger G, Bereiter-Hahn J, Jendrach M. Decreased expression of Drp1 and Fis1 mediates mitochondrial elongation in senescent 
cells and enhances resistance to oxidative stress through PINK1. J Cell Sci. 2010;123(6):917-26. https://doi.org/10.1242/jcs.059246

137. Dalle Pezze P, Nelson G, Otten EG, Korolchuk VI, Kirkwood TBL, von Zglinicki T, et al. Dynamic modelling of pathways to cellular senescence reveals strategies for targeted interventions. PLoS Comput Biol. 2014;10(8):e1003728. https://doi.org/10.1371/journal.pcbi.1003728

138. Kaplon J, Zheng L, Meissl K, Chaneton B, Selivanov VA, Mackay G, et al. A key role for mitochondrial gatekeeper pyruvate dehydrogenase in oncogeneinduced senescence. Nature. 2013;498(7452):109-12. https://doi.org/10.1038/nature12154

139. Correia-Melo C, Marques FD, Anderson R, Hewitt G, Hewitt R, Cole J, et al. Mitochondria are required for pro-ageing features of the senescent phenotype. EMBO J. 2016;35(7):724-42. https://doi.org/10.15252/embj.201592862

140. Vizioli MG, Liu T, Miller KM, Robertson N, Gilroy K, Lagnado AB, et al. Mitochondria-to-nucleus retrograde signaling drives formation of cytoplasmic chromatin and inflammation in senescence. Genes Dev. 2020;34(5-6):428-45. https://doi.org/10.1101/gad.331272.119

141. Covarrubias AJ, Lopez-Dominguez JA, Perrone R, Kale A, Newman J, Iyer SS, et al. Aging-related inflammation driven by cellular senescence enhances NAD consumption via activation of $\mathrm{CD}^{+} 8^{+}$macrophages. bioRxiv 609438 [Preprint]. 2019 Jul 31. https://doi.org/10.1101/609438

142. Yoshino J, Baur JA, Imai S. NAD ${ }^{+}$intermediates: The biology and therapeutic potential of NMN and NR. Cell Metab. 2018;27(3):513-28. https://doi.org/10.1016/j.cmet.2017.11.002

143. Verdin E. $\mathrm{NAD}^{+}$in aging, metabolism, and neurodegeneration. Science. 2015;350(6265):1208-13. https://doi.org/10.1126/science.aac4854

144. Mills KF, Yoshida S, Stein LR, Grozio A, Kubota S, Sasaki Y, et al. Long-term administration of nicotinamide mononucleotide mitigates age-associated physiological decline in mice. Cell Metab. 2016;24(6):795-806. https://doi.org/10.1016/j.cmet.2016.09.013

145. Airhart SE, Shireman LM, Risler LJ, Anderson GD, Nagana Gowda GA, Raftery D, et al. An open-label, non-randomized study of the pharmacokinetics of the nutritional supplement nicotinamide riboside (NR) and its effects on blood $\mathrm{NAD}^{+}$levels in healthy volunteers. PLoS One. 2017;12(12):e0186459. https://doi.org/10.1371/journal.pone.0186459

146. Schultz MB, Sinclair DA. Why $\mathrm{NAD}^{+}$declines during aging: It's destroyed. Cell Metab. 2016;23(6):965-6. https://doi.org/10.1016/j.cmet.2016.05.022

147. Clement J, Wong M, Poljak A, Sachdev P, Braidy N. The plasma $\mathrm{NAD}^{+}$ metabolome is dysregulated in "normal" aging. Rejuvenation Res. 2019;22(2):121-30. https://doi.org/10.1089/rej.2018.2077

148. Liu L, Su X, Quinn WJ, Hui S, Krukenberg K, Frederick DW, et al. Quantitative analysis of NAD synthesis-breakdown fluxes. Cell Metab. 2018;27(5):106780.e5. https://doi.org/10.1016/j.cmet.2018.03.018

149. Cameron AM, Castoldi A, Sanin DE, Flachsmann LJ, Field CS, Puleston DJ, et al. Inflammatory macrophage dependence on $\mathrm{NAD}^{+}$salvage is a consequence of 
reactive oxygen species-mediated DNA damage. Nat Immunol. 2019;20(4):420-32. https://doi.org/10.1038/s41590-019-0336-y

150. Travelli C, Colombo G, Mola S, Genazzani AA, Porta C. NAMPT: A pleiotropic modulator of monocytes and macrophages. Pharmacol Res. 2018;135:25-36. https://doi.org/10.1016/j.phrs.2018.06.022

151. Camacho-Pereira J, Tarragó MG, Chini CCS, Nin V, Escande C, Warner GM, et al. CD38 dictates age-related NAD decline and mitochondrial dysfunction through an SIRT3-dependent mechanism. Cell Metab. 2016;23(6):1127-39. https://doi.org/10.1016/j.cmet.2016.05.006

152. Quarona V, Zaccarello G, Chillemi A, Brunetti E, Singh VK, Ferrero E, et al. CD38 and CD157: A long journey from activation markers to multifunctional molecules. Cytom Part B Clin Cytom. 2013;84B(4):207-17. https://doi.org/10.1002/cyto.b.21092

153. Zhao YJ, Lam CMC, Lee HC. The membrane-bound enzyme CD38 exists in two opposing orientations. Sci Signal. 2012;5(241):ra67. https://doi.org/10.1126/scisignal.2002700

154. Shu B, Feng Y, Gui Y, Lu Q, Wei W, Xue X, et al. Blockade of CD38 diminishes lipopolysaccharide-induced macrophage classical activation and acute kidney injury involving NF- $\kappa B$ signaling suppression. Cell Signal. 2018;42:24958. https://doi.org/10.1016/j.cellsig.2017.10.014

155. Amici SA, Young NA, Narvaez-Miranda J, Jablonski KA, Arcos J, Rosas L, et al. CD38 Is robustly induced in human macrophages and monocytes in inflammatory conditions. Front Immunol. 2018;9:1593. https://doi.org/10.3389/fimmu.2018.01593

156. Kincaid B, Bossy-Wetzel E. Forever young: SIRT3 a shield against mitochondrial meltdown, aging, and neurodegeneration. Front Aging Neurosci. 2013;5:48. https://doi.org/10.3389/fnagi.2013.00048

157. Pence BD, Yarbro JR. Aging impairs mitochondrial respiratory capacity in classical monocytes. Exp Gerontol. 2018;108:112-7. https://doi.org/10.1016/j.exger.2018.04.008

158. Fahy GM, Brooke RT, Watson JP, Good Z, Vasanawala SS, Maecker H, et al. Reversal of epigenetic aging and immunosenescent trends in humans. Aging Cell. 2019;18:e13028. https://doi.org/10.1111/acel.13028

159. Ong S-M, Hadadi E, Dang T-M, Yeap W-H, Tan CT-Y, Ng T-P, et al. The proinflammatory phenotype of the human non-classical monocyte subset is attributed to senescence. Cell Death Dis. 2018;9(3):266. https://doi.org/10.1038/s41419-018-0327-1

160. Salminen A, Kauppinen A, Kaarniranta K. Emerging role of NF- $\kappa B$ signaling in the induction of senescence-associated secretory phenotype (SASP). Cell Signal. 2012;24(4):835-45. https://doi.org/10.1016/j.cellsig.2011.12.006

161. Kang BN, Tirumurugaan KG, Deshpande DA, Amrani Y, Panettieri RA, Walseth $\mathrm{TF}$, et al. Transcriptional regulation of CD38 expression by tumor necrosis factor- $\alpha$ in human airway smooth muscle cells: Role of NF- $\kappa B$ and sensitivity to glucocorticoids. FASEB J. 2006;20(7):1000-2. https://doi.org/10.1096/fj.054585fje 
162. Du Y, Dai Q, Zhang H, Li Q, Song K, Fu Y, et al. CD38 deficiency downregulates the onset and pathogenesis of collagen-induced arthritis through the NF- $\kappa B$ Pathway. J Immunol Res. 2019;2019:1-9. https://doi.org/10.1155/2019/7026067

163. Mangerich A, Bürkle A. Pleiotropic cellular functions of PARP1 in longevity and aging: Genome maintenance meets inflammation. Oxid Med Cell Longev. 2012;2012:1-19. https://doi.org/10.1155/2012/321653

164. Hurtado-Bagès S, Knobloch G, Ladurner AG, Buschbeck M. The taming of PARP1 and its impact on $\mathrm{NAD}^{+}$metabolism. Mol Metab. 2020. https://doi.org/10.1016/j.molmet.2020.01.014

165. Liu L, Ke Y, Jiang X, He F, Pan L, Xu L, et al. Lipopolysaccharide activates ERKPARP-1-RelA pathway and promotes nuclear factor- $\kappa \mathrm{B}$ transcription in murine macrophages. Hum Immunol. 2012;73(5):439-47. https://doi.org/10.1016/j.humimm.2012.02.002

166. Yang Z, Li L, Chen L, Yuan W, Dong L, Zhang Y, et al. PARP-1 Mediates LPSInduced HMGB1 Release by Macrophages through Regulation of HMGB1 Acetylation. J Immunol. 2014;193(12):6114-23. https://doi.org/10.4049/jimmunol.1400359

167. Bock FJ, Chang P. Macrophage Activation: On PAR with LPS. Chem Biol. 2015;22(4):432-3. https://doi.org/10.1016/j.chembiol.2015.04.006

168. Fang EF, Lautrup S, Hou Y, Demarest TG, Croteau DL, Mattson MP, et al. NAD ${ }^{+}$ in aging: Molecular mechanisms and translational implications. Trends Mol Med. 2017;23(10):899-916. https://doi.org/10.1016/j.molmed.2017.08.001

How to cite this article:

Yarbro JR, Emmons RS, Pence BD. Macrophage Immunometabolism and Inflammaging: Roles of Mitochondrial Dysfunction, Cellular Senescence, CD38, and NAD. Immunometabolism. 2020;2(3):e200026. https://doi.org/10.20900/immunometab20200026 